\title{
Practical Experience with the Methodology of Prediction of Corrosion-Fatigue Failures of Steam Turbine Rotating Blades
}

\author{
Josef Kasl $^{1 *}$, Jan Lazar ${ }^{1}$, and Miroslava Matějová ${ }^{1}$ \\ ${ }^{1}$ Research and testing institute Plzeň Ltd., Tylova 1581/46, 30100 Plzeň, Czech Republic
}

\begin{abstract}
Corrosion fatigue fractures initiating from corrosion pits are one of the most serious problem during service of rotating blades of the low-pressure parts of steam turbines. A methodology for fatigue failure prediction, originally based on the knowledge obtained by EPRI (Electric Power Research Institute), using corrosion pits parameters assessment and local stresses calculation was adapted to the conditions of ČEZ a.s. power stations. This contribution deals with the evaluation of the corrosion state of blades of three low pressure rotors after long service. Measurement was done in power stations equipped with turbines of power $200 \mathrm{MW}$ and 110 MW respectively. Possibilities and uncertainties (influence of filling of pits with oxides, cyclic stress calculations, and the selection of the geometric factor $Y$ ) and their elimination are discussed.
\end{abstract}

\section{Introduction}

Many accidents at thermal power plant units are associated with turbine failures. One of the most significant problems of the flow part of low pressure (LP) components parts of turbines is stress corrosion cracking and/or corrosion fatigue. These cracks, which most often develop from initial corrosion pits (CPs), are usually related to the presence of a higher number of corrosively aggressive impurities in the steam that accumulate in a film on the surface of the components during operation or during shutdowns in the wet parts of turbines.

In the 1970s, failures of the rotating blades of low-pressure rotors affected steam turbines in thermal power plants operated by ČEZ a.s. (producer and distributor of electricity in the Czech Republic). Therefore, there has been intensive research into the causes of these problems and efforts to eliminate them. In principle, it is possible to use three options or their combination: a reduction of corrosion-inducing substances in steam, a production of blades from more corrosion-resistant materials and a development of nondestructive tests for diagnostics of dangerous condition of the rotor. In particular, the first two options were applied and there was a significant improvement in the long period without accidents.

* Corresponding author: kasl@,vzuplzen.cz 
However, over the last few years, corrosion fatigue fractures initiating from CPs have been a root cause of failures in several $200 \mathrm{MW}$ turbines in power stations operated by ČEZ a.s. ČEZ a.s. has been a member of the P65 program of the Electric Power Research Institute (EPRI) in the USA since 2014. To solve problems with blade accidents, ČEZ a.s. has risen to the occasion that EPRI has developed a methodology that has made it possible to assess the development of fatigue cracks from CPs and has decided to adapt this methodology to the conditions of its power stations. Many years effort by EPRI to elaborate this methodology has been concentrated on its Program on Technology Innovation: "Development of a Corrosion-Fatigue Prediction Methodology for Steam Turbine Blades". Its results are summarised in the EPRI technical reports [1-3]. Based on these facts, the project "Turbines - development of a methodology for checking blades using information from EPRI" was proposed and subsequently successfully solved. However, the development of the EPRI methodology was carried out on the basis of laboratory tests and the procedure was not tested in real conditions on the operated blades. So, the practical application of the EPRI procedure brings many new aspects and problems.

This paper points out the problematic areas of the method and provides information about the experience with its practical use.

\section{Methodology}

The central idea for elaborating the EPRI methodology is the precondition that the CPs created on the surface of the blade make notches, and by using the methods of linear fracture mechanics it is possible to find out the values of the stress and notch size under which a crack does not spread. It is supposed that it is sufficient to characterize fatigue parameters of the given blade material with just two parameters, i.e. smooth (without notches) specimen endurance limit, $\sigma_{\mathrm{ac}}$, and threshold cyclic stress intensity limit, $\Delta K_{\mathrm{th}}$, determined in the open air at a temperature of $80{ }^{\circ} \mathrm{C}$. The EPRI project was focused on finding the critical values of mutually related pairs - the size of the $\mathrm{CP}$ and stress at the place of occurrence of the CP under which the initiation and growth of a fatigue crack does not occur.

The basis for evaluating these two critical parameters is the Kitagawa-Takahashi diagram [4] modified by El Haddad (KTHD) [5]. KTHD contains two 'Kitagawa lines' in the coordinates of stress vs. the notch size (the depth of the CP) and 'El Haddad curve' to which the Kitagawa lines create asymptotes. An example of KTHD is shown in Fig. 2. The curves are the material characteristics for the given stress ratio parameter $R$ :

$$
R=\sigma_{\min } / \sigma_{\max }=\left(\sigma_{\mathrm{m}}-\sigma_{\mathrm{a}}\right) /\left(\sigma_{\mathrm{m}}+\sigma_{\mathrm{a}}\right)
$$

when it is considered that loading is carried out between two constant levels of stress maximum $\sigma_{\max }$ and minimum $\sigma_{\min }$ which determine the amplitude of stress, $\sigma_{a}$, and mean stress, $\sigma_{\mathrm{m}}$. These three lines subdivide KTHD into three areas: above the Kitagawa lines where the cracks initiated in the CPs will grow, below El Haddad line where he cracks may initiate in the CPs but will not grow, and between them, where it is possible that the cracks will most probably develop. A more detailed description is given in the previous contribution [6]. 


\section{Results}

\subsection{Application of the methodology}

The procedure consists of several successive steps. Its scheme is shown in Fig. 1. Before the actual measurement, the fatigue parameters of the materials of the tested blades are determined and models for the calculation of static and cyclic stress by the finite element method (FEM) of the blades are developed (steps 1 and 2). The experimental values of $\sigma_{\mathrm{ac}}$ and $\Delta K_{\text {th }}$ were determined for the several values of parameter $R$. Approximation by the Gerber parabola was used to calculate the endurance limit and a polynomial of the third order for threshold cyclic stress intensity limit for require value of $R$. For the measured rotor it is necessary to obtain information about its production, previous operation and outlook for further one (step 3). Laser scanning performed in segments on individual wheels proved to be the most aqueous method for measuring the parameters of corrosion pits. The width, $2 c$, and depth, $a$, of the $\mathrm{CP}$ and its $x, y, z$ coordinates on the surface of blade are determined (step 4). In inaccessible places, measurements are made using replicas. Static $\sigma_{m}$ and cyclic $\sigma_{\mathrm{a}}$ stresses are calculated (step 5) and the value of the parameter $R$ is determined from them (step 6). Stress endurance strength and threshold cyclic stress intensity limit are determined for calculated parameter $R$ (step 7). The KTHD is constructed using the procedure processed in Excel (step 8). The following is an assessment of the condition of the CPs with regard to its danger of being a source of fatigue cracks (step 9).
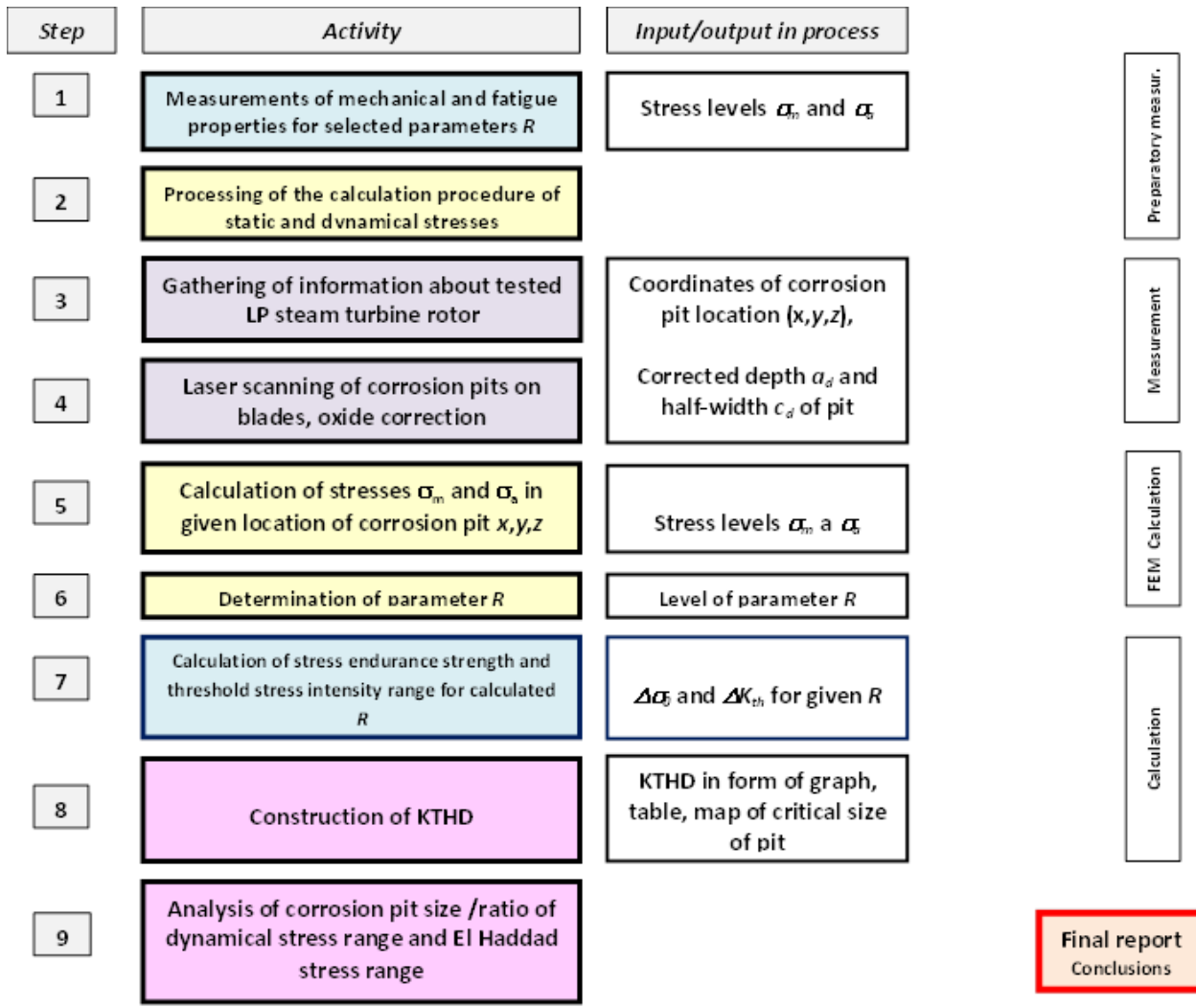

Fig. 1. Chart of the procedure. 
KTHD were constructed for the following steels: X12Cr13, X22CrMoV121 (1.4923), 1.4938 (X12CrNiMoV12-3/Böhler T552 /1.4939/X12CrNiMo12), Böhler T509, and Böhler T671, for the blades of stages L-0 and L-1 for 13 models of the blades of the turbines with outputs 110,200,250, 270 and $660 \mathrm{MW}$ operated on power stations of ČEZ a.s.

The direct graphic output of the methodology is a plotted KTHD with the marked position-image of the respective CP (in coordinates the depth of the defect, $a_{\mathrm{d}}$, and the range of the cyclic stress component, $\Delta \sigma_{\mathrm{d}}$ ). The decisive factor is the position of this KD image with respect to the El Haddad curve resp. against the Kitagava lines. From it, it is possible to predict the potential of this $\mathrm{CP}$ for the fatigue crack to propagate from it. This display is highly intuitive, but not very practical for monitoring a larger number of CPs, as it depends on the ratio $R$ (given by the magnitudes of the static and cyclic stress components). Quantitatively, the $\mathrm{CP}$ can be characterized either by the ratio of the range of the cyclic stress component at the CP, $\Delta \sigma_{\mathrm{d}}$, to the stress on the El Haddad curve (critical stress), $\Delta \sigma_{\mathrm{dc}}$, corresponding to the position of the CP depth, $a_{\mathrm{d}}: \Delta \sigma_{\mathrm{d}} / \Delta \sigma_{\mathrm{dc}}$, or the ratio of the (corrected) depth of the $\mathrm{CP}, a_{\mathrm{d}}$, to the critical depth of the $\mathrm{CP}, a_{c}$ (at the same applied stress, $\left.\Delta \sigma_{\mathrm{d}}\right)$ resp. the ratios of the logarithms of these variables. The first option (ratio labelled as parameter $P$ ) is used to evaluate the CPs in this procedure. An example of this output and variables are shown in Fig. 2. It is more practical to display calculations resp. outputs in a clear tabular form in the form of an Excel table (see Table 1). Each row of the table belongs to one $\mathrm{CP}$ and all calculations of relevant KTHD parameters for the given $\mathrm{CP}$ conditions are performed in it. The next option is a graphical record - a map of the distribution of the critical size of the depth, $a_{\mathrm{c}}$, of the $\mathrm{CP}$ in the form of various colour levels drawn directly on the projection of the blade model. This procedure is again very illustrative and it is appropriate to use it for the initial estimation of the "criticality" of the $\mathrm{CP}$ in a given position.

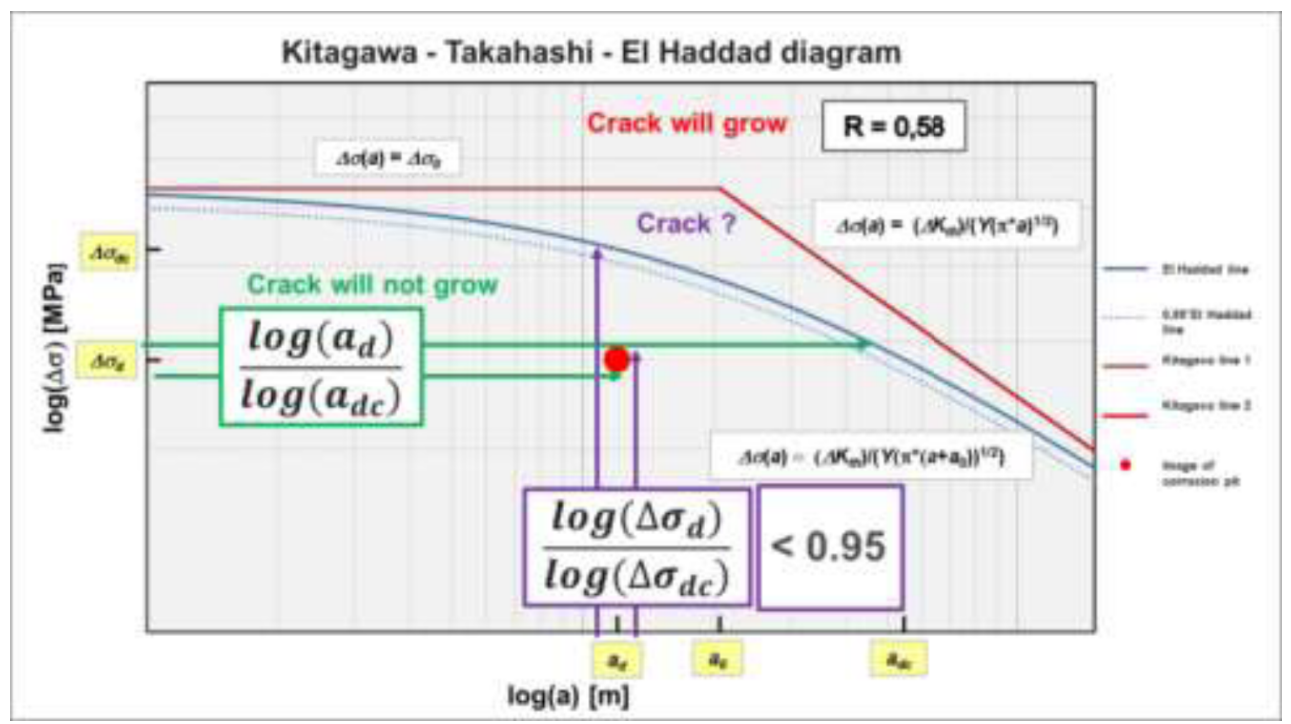

Fig. 2. Kitagawa-Takahashi-El Haddad Diagram and possible quantitative assessment of CP. 


\subsection{Uncertainties of the methodology}

There are a number of uncertainties in individual steps of evaluating process of the disposition of CPs for the development of fatigue cracks. They can significantly affect the reliability and explanatory power of the method. This must be considered when the results are interpreted.

The condition of KTHD construction is based on the knowledge of two basic material parameters describing the fatigue properties of a given blade steel. They are determined experimentally only for a limited number of values of the asymmetry parameter, $R$, for a specific material. However, it is necessary to know these parameters for any value of R. So it is necessary to calculate these values from the regression equations. In principle, their accuracy will be better the more experimental data (for various $R$ ) are available and the more accurate model is selected. This risk can therefore be eliminated by increasing the number of performed tests, which of course encounters time and money problems with the need for more fatigue tests.

The first serious problem is the determination of the geometric parameters (dimensions) of $\mathrm{CP}$. The most suitable procedure of their characterization for turbine blades on disc is use of the $3 \mathrm{D}$ arm laser scanner. It is possible to detect CPs with dimension above $50 \mu \mathrm{m}$. In general, various parameters can be used to characterize the notch effect of a CP: pit depth, pit width, or some linearized parameter of the VAREA type (square root of the maximum notch area perpendicular to the direction of the main stress). All three options were tested. It has proven to be most advantageous to measure the depth, which is determined more accurately than the width. CPs show irregular and complicated shape and they are often filled with oxidation products and deposited material (Fig. 3). They can strongly influence the values of CP depth. These fillings remain largely retained after standard cleaning during rotor maintenance. Cleaning with other media was therefore attempted. Better results were obtained with dry ice cleaning. However, its use in power plant conditions was problematic. Other NDT methods were also tested (among others use of flexible eddy current probe). The results obtained are promising, but the method is laborious and time consuming. Currently, a correction equation is used to estimate the actual depth from the measured value of the depth. This correction procedure was processed on the basis of a metallographic analysis of more than $1000 \mathrm{CPs}$, during which the maximum depth of the pit without filling and including it was measured.

Another problematic point is the determination of the geometric factor $Y$. During the development of the EPRI methodology, the rigorous determination of the $Y$ value by calculation was resigned, and it was determined so that the experimental test results of samples with artificially prepared pits of a given size were "placed" in the KTHD as best as possible, i.e. the pits of failed samples were above the El Haddad curve and un-cracked below it. In order to determine the geometric factor $Y$, the procedure in described method was "similar". Data of four "critical" CPc from known failed blades were available. They were used to adjust the value of the $Y$ factor so that the images of these pits in the KTHD lie in the critical area, and all images of corrosion pits measured so far (for blades without cracks) lie in the non-critical part of KTHD. At the same time, this procedure was used to select the most suitable correction equation for estimating the depth of the CP for several types of tested correction equations and the values of numerical parameters of these equations. The optimized value of the geometric parameter is 0.45 and linear correction equation is used.

The calculation of the relevant static and dynamic stresses at the location of the CP by mathematical modelling of FEM is one of the key steps in the whole methodology. While the calculation of static stress can be considered quite reliable, the calculation of cyclic stress is problematic. Since excitation of blades is not exactly known, it is not clear which 
vibration mode of the blades to choose and what are the real terminal deflections of the blades during turbine operation. However, from the point of view of fatigue failure, the maximum deviations in critical states and the durations of these states are essential. Unfortunately, information on these parameters is not known from the operational measurements for all blade types and for all possible operating modes. In this methodology, the following initial conditions were chosen: the oscillation of the first oven shape with a nodal diameter of 0 , the deflection of the tip of the blade equal to $1 \mathrm{~mm}$. It should be noted that the experimental data are not entirely sufficient for this choice. For CPs positions, therefore, stresses are also calculated for other vibration modes. Conservatively, worse stresses are used. The stress at a given location is also taken to be the maximum of those calculated for the four nearest mesh points to the CP position.

Another necessary condition for the successful use of the methodology is knowledge of the history and long-term view of the turbine operation (number of start-ups, shot-downs, operating times at limited power, etc.).
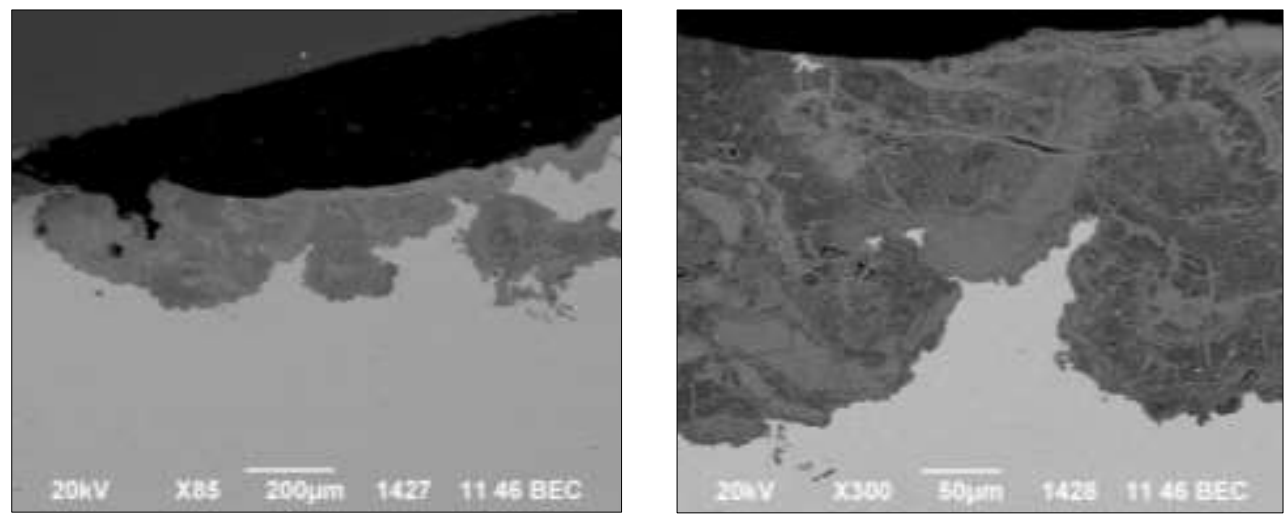

Fig. 3. Corrosin pit (scanning electron microscopy).

\subsection{Application at power stations}

Calculations and results of KTHD from measurements at power plants are processed in tabular form using an Excel calculator. An example of overviews of measured and calculated results from measuring the $4^{\text {th }}$ disk of LP rotor from the ETU power plant is given in Table 1. The table also includes results for four CPs from failed blades (marked from T1 to T4). The basic parameter in the methodology is considered to be the ratio $P$ of the range of the cyclic stress in the pit position and the stress range of the El Haddad curve (for a given depth of the pit) resp. ratio of their logarithms. So, the results are sorted according to the "dangerous character" of CPs according to this parameter. To increase the conservatism of the method, the value 1.00 was not taken as the limit of parameter $P$, but the value 0.95 was chosen. It can be seen from Table 1 that the parameter $P$ is well below this value for all tested CPs (maximum value found is about 0.75 ). Conversely, the values of this parameter are above this value for the initial CPs of the failed blades. The fact that the CP depths are small and that they lie in places with low stress values contributed to the low values of $P$ in this case. The worst CPs on the blades reach from $1 \%$ to $2 \%$ of the relevant critical depth of the $\mathrm{CP}$.

Table 2 summarizes selected results from the measurement and evaluation of CPs so far performed on NT rotors from the EDE, ELE and ETU power plants. Very small corrosion attack was found on the blades from the ELE power plant, the worst state was in the blades 
from the EDE power plant. For them, some CPs are close to the risk situation. The condition of the blades is mainly influenced by the rotor operating time (the longest at the EDE power plant - 162,000 operating hours, the shortest at the ETU power plant 62,000 operating hours), blade material (X12Cr13 steel at the EDE power plant, X12CrNiMoV123 at the ETU power plant) and the state of steam management.

Table 1. Results of CP assessment at power station ETU

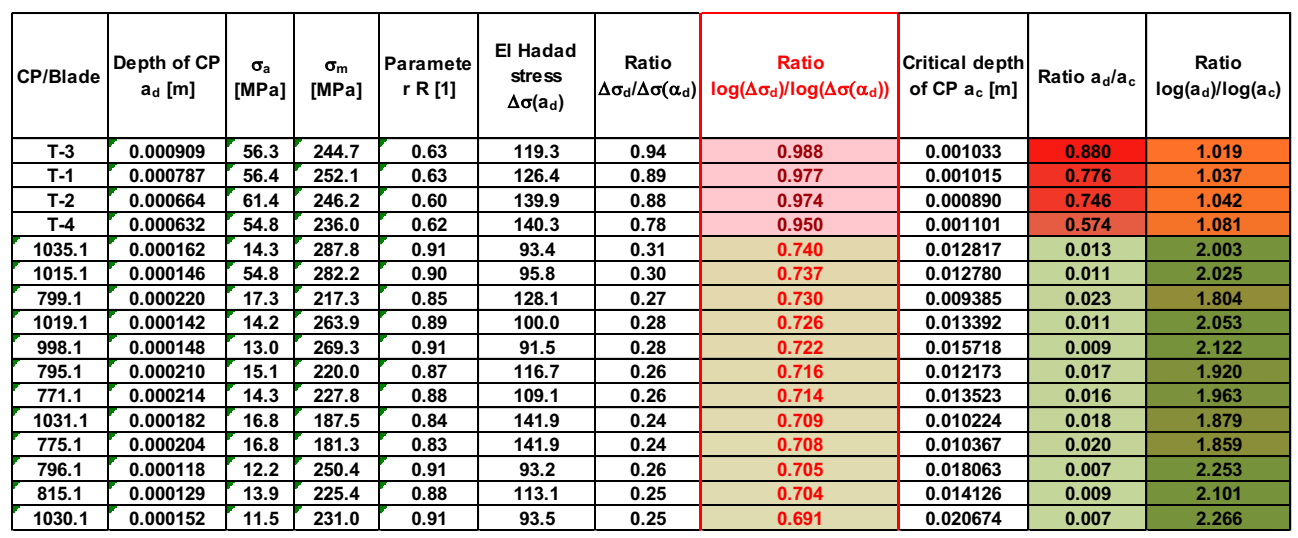

Table 2. Comparison of results of $\mathrm{CP}$ assessment at power stations EDE, ELE, and ETU

\begin{tabular}{|c|c|c|c|c|c|c|c|c|c|}
\hline Disk & & $\sigma_{\mathrm{m}}[\mathrm{MPa}]$ & $\sigma_{\mathrm{a}}[\mathrm{MPa}]$ & $\begin{array}{c}\text { Parameter } \\
\text { R [1] }\end{array}$ & $\begin{array}{c}\text { Depth of pit } \\
a_{d}[\mathrm{~m}]\end{array}$ & $\begin{array}{c}\text { Critical } \\
\text { depth of } \\
\text { pit } a_{c}[\mathrm{~m}]\end{array}$ & $\begin{array}{r}\text { Ratio } \\
a_{d} / a_{c}\end{array}$ & \begin{tabular}{c|} 
Ratio \\
$\Delta \sigma_{\mathrm{d}} / \Delta \sigma($ \\
$\left.\alpha_{\mathrm{d}}\right)$ \\
\end{tabular} & $\begin{array}{c}\text { Ratio } \\
\log \left(\Delta \sigma_{\mathrm{d}}\right) / \log ( \\
\left.\Delta \sigma\left(\alpha_{\mathrm{d}}\right)\right) \\
\end{array}$ \\
\hline \multicolumn{10}{|c|}{ EDE 2019} \\
\hline \multirow{3}{*}{3} & Max & 300 & 77 & 0.94 & \begin{tabular}{|l|}
0.000448 \\
\end{tabular} & 2.515651 & 0.350 & 0.757 & 0.948 \\
\hline & Min & 11 & 1 & 0.51 & 0.000093 & 0.000408 & 0.000 & 0.021 & 0.162 \\
\hline & Průmèr & 165 & 26 & 0.75 & 0.000161 & 0.053988 & 0.060 & 0.345 & 0.743 \\
\hline \multirow{3}{*}{ 3a } & Max & 300 & 77 & 0.94 & 0.000559 & 17.122000 & 0.440 & 0.758 & 0.946 \\
\hline & Min & 3 & 0 & 0.51 & 0.000091 & 0.000000 & 0.000 & 0.007 & -0.055 \\
\hline & Průmèr & 158 & 24 & 0.76 & $\begin{array}{l}0.000170 \\
\end{array}$ & 0.154000 & 0.052 & 0.327 & 0.720 \\
\hline \multicolumn{10}{|c|}{ ELE 2020} \\
\hline \multirow{3}{*}{ 3a } & Max & 142 & 126 & 0.36 & 0.000091 & 0.024870 & 0.065 & 0.757 & 0.884 \\
\hline & Min & 21 & 33 & -0.26 & 0.000040 & 0.000620 & 0.002 & 0.021 & 0.667 \\
\hline & Průmèr & 69 & 55 & 0.07 & 0.000061 & 0.009657 & 0.022 & 0.345 & 0.738 \\
\hline \multirow{3}{*}{4} & $\operatorname{Max}$ & 199 & 38 & 0.92 & 0.000229 & 0.093790 & 0.063 & 0.758 & 0.800 \\
\hline & Min & 27 & 5 & 0.61 & 0.000051 & 0.001815 & 0.001 & 0.007 & 0.427 \\
\hline & Prưmèr & 162 & 18 & 0.8 & 0.000084 & 0.016464 & 0.014 & 0.327 & 0.675 \\
\hline \multirow{3}{*}{$4 a$} & $\operatorname{Max}$ & 179 & 32 & 0.89 & 0.000150 & 0.034201 & 0.051 & 0.295 & 0.770 \\
\hline & Min & 131 & 8 & 0.69 & 0.000055 & 0.002584 & 0.002 & 0.141 & 0.600 \\
\hline & Průměr & 161 & 22 & 0.77 & 0.000098 & 0.011079 & 0.023 & 0.227 & 0.704 \\
\hline \multicolumn{10}{|c|}{ ETU 2021} \\
\hline \multirow{3}{*}{4} & Max & 288 & 17 & 0.91 & \begin{tabular}{|l|}
0.000182 \\
\end{tabular} & 0.020674 & 0.018 & 0.307 & 0.740 \\
\hline & Min & 188 & 11 & 0.84 & 0.000143 & 0.010224 & 0.007 & 0.236 & 0.691 \\
\hline & Prủměr & 238 & 14 & 0.87 & 0.000163 & 0.015449 & 0.013 & 0.272 & 0.715 \\
\hline \multirow{3}{*}{$4 a$} & $\operatorname{Max}$ & 250 & 17 & 0.91 & 0.000220 & 0.018063 & 0.023 & 0.270 & 0.730 \\
\hline & Min & 181 & 12 & 0.83 & 0.000118 & 0.009385 & 0.007 & 0.235 & 0.704 \\
\hline & Prüměr & 220 & 15 & 0.87 & 0.000183 & 0.012940 & 0.015 & 0.256 & 0.713 \\
\hline \multicolumn{10}{|c|}{ Failed blades } \\
\hline \multirow{3}{*}{$\begin{array}{l}\text { Failed } \\
\text { blades }\end{array}$} & Max & 252 & 61 & \begin{tabular}{|l|}
0.63 \\
\end{tabular} & \begin{tabular}{|l|}
0.000909 \\
\end{tabular} & 0.001101 & 0.880 & 0.944 & 0.988 \\
\hline & Min & 236 & 55 & 0.60 & 0.000632 & 0.000890 & 0.574 & 0.781 & 0.950 \\
\hline & Prủměr & 245 & 57 & 0.62 & 0.000748 & 0.001010 & 0.744 & 0.874 & 0.972 \\
\hline
\end{tabular}




\section{Summary}

This article describes practical experience with the application of the method of evaluation of corrosion attack of steam turbine blades. The method evaluates the hazard of corrosionfatigue cracks propagation from corrosion pits during service of low pressure rotors. If a high probability of crack initiation is identified during the inspection and the relevant blade is replaced, high economic losses can be avoided.

During the development and industrial application of this method, uncertainties of some input measured and calculated parameters were found, which can significantly affect the reliability of results. The most important input data with a high degree of uncertainty include the following: the calculation of the cyclic stress at the location of the corrosion pit, the correct determination of the actual depth of the corrosion pit and the choice of the value of the geometric parameter $Y$ in the relevant equations. The amount of uncertainty is eliminated by using of a conservative approach in all steps of the procedure. Fitting of the parameter $Y$ and correction parameters of the relation used for the corrosion pits depth correction was done. After this fitting all measured values of corrosion pits on crack-free blades were in the safe region of KTHD, while parameters of corrosion pits from which corrosion cracks were initiated on failed blades were in the risk one.

The following parameters are used in the procedure:

Measured parameter of pit: depth of pit; oxide correction: regression equation: corrected depth of pit $=\left(0.88^{*}\right.$ measured depth of pit $)+75[\mu \mathrm{m}]$; geometric parameter: $\mathrm{Y}=0.45$; dynamical stresses are re-count on the blade terminal deflection $1 \mathrm{~mm}$.

This work has been carried out with the financial support of the project TN01000007.

\section{References}

1. Program on Technology Innovation: Development of a Corrosion-Fatigue Prediction Methodology for Steam Turbines: Experimental results 2009-2010. EPRI, Palo Alto, CA: 2010. 1023196

2. Program on Technology Innovation: Development of a Corrosion-Fatigue Prediction Methodology for Steam Turbine Blades: AISI 403/410 $(12 \% \mathrm{Cr})$ and $17-4 \mathrm{PH}$ Blade Steels. EPRI, Palo Alto, CA: 2013. 10256208

3. Program on Technology Innovation: Development of a Corrosion-Fatigue Prediction Methodology for Steam Turbine Blades: AISI 403/410 $(12 \% \mathrm{Cr})$ and $17-4 \mathrm{PH}$ Blade Steels. EPRI, Palo Alto, CA: 2015. 3002005107

4. H. Kitagawa, S. Tahashi, Proc. of the Second International Conference on Mechanical Behavior of Materials. Metals Park, OH: American Society for Metals; p. 627 (1976)

5. M. El Haddad, T.H. Topper, N. Smith, ASME Engrg. Matls. Technol. 103, 91 (1981)

6. J. Kasl, M. Matějová, J. Mrštík: Failure analysis of Rotating Blades of Low-pressure Steam Turbine Rotors and Possibility of Prediction Corrosion-fatigue Ruptures. MATEC Web of Conferences 188. 04020 (2018) ICEAF-V 2018. https://doi.org/10.1051/matecconf/201818804020 